\title{
EDUCAÇÃO AMBIENTAL E O PLANEJAMENTO DA PAISAGEM
}

\author{
Felipe Timmermann Gonçalves ${ }^{1}$ \\ João Carlos $\mathrm{Nucci}^{2}$ \\ Simone Valaski ${ }^{3}$
}

Resumo: Fundamentado nas bases do Planejamento da Paisagem, apresentase a possibilidade do uso da metodologia para mapeamento da cobertura do solo urbano, que classifica as estruturas da paisagem que influenciam positiva ou negativamente a qualidade ambiental urbana, e pode ser trabalhada na Educação Ambiental. Entende-se que, a inserção da temática na educação dos alunos, traz benefícios ao interesse da população quanto ao planejamento e gestão das cidades. O trabalho utilizou a metodologia para classificar a paisagem do bairro Portão, em Curitiba/Pr, e se apresentou como boa ferramenta para abordagens interdisciplinares a partir do ambiente cotidiano dos alunos.

Palavras-chave: Planejamento Urbano; Qualidade Ambiental; Mapeamento de Biótopos; Participação Popular; Interdisciplinaridade.

\footnotetext{
${ }^{1}$ Universidade Federal do Paraná. E-mail: fftimmer@gmail.com

2 Universidade Federal do Paraná. E-mail: nucci@ufpr.br

3 Universidade Federal do Paraná. E-mail: simonevalaski@ig.com.br

Revbea, São Paulo, V. 11, № 1: 37-53, 2016.
}

revista brasileira educação ambiental 


\section{Introdução}

Nas últimas décadas as cidades brasileiras sofreram incremento populacional atrelado a políticas urbanas de adensamento que se basearam somente na disponibilidade de infraestrutura e de espaços físicos, omitindo a preocupação com a qualidade ambiental. Tal pensamento de curto prazo tem seus resultados evidenciados em problemas de ordem social e ambiental em todas as grandes cidades, como poluição, tráfego pesado, enchentes, saturação da infraestrutura, inexistência de espaços públicos livres disponíveis a todos, desrespeito ao ecossistema local, a falta de opções de contato da população com a natureza e tantos outros.

A necessidade de um planejamento, com base em uma visão integradora entre infraestrutura e proteção dos sistemas naturais, é cada vez mais urgente nos centros urbanos, que historicamente se desenvolveram sob uma perspectiva que não levava em conta os aspectos naturais, dos quais a sociedade humana depende para seu bem-estar. Assim, o Planejamento da Paisagem, sendo um instrumento de planejamento, desenvolvido e aplicado na Alemanha desde a década de 1970 (KIEMSTED et al., 1998) e que considera a potencialidade da natureza como forma de promoção da qualidade de vida da população, poderia acrescentar uma nova visão de planejamento no Brasil.

A demanda por pesquisas e políticas públicas, a fim de conter o desenvolvimento voltado apenas aos interesses econômicos, resultou, em 1976, na institucionalização do Planejamento da Paisagem como política do estado Alemão, voltada às áreas urbanas e rurais. Tal instrumento busca, portanto, a diminuição dos impactos sobre o potencial da natureza e manutenção da capacidade das funções ecológicas da paisagem (BELEM, 2013).

Tanto em lei federal brasileira, como no Planejamento da Paisagem na Alemanha, a importância da transparência e consulta às necessidades populares é evidenciada, e só com ela decisões podem ser tomadas de modo mais claro, compreensível e transparente, resultando em maior aprovação da população e implementação indubitável das ações planejadas. Nesta necessidade de participação popular, criar a cultura do interesse pelo planejamento é algo de suma importância para a qualificação e democratização em longo prazo de todo o processo. Portanto, o sistema de ensino, entendido como importante aparelho de difusão ideológica, passa a ser palco de discussões, fundamental à implementação do Planejamento da Paisagem no Brasil.

Sob a perspectiva de um ambientalismo carregado de significados políticos, e considerando o sistema de ensino como transmissor de ideologias, a dimensão ambiental no ensino é uma modalidade destinada a ocupar todos os espaços pedagógicos possíveis no tecido social, visando atingir todos os humanos em todos os seus momentos de vida (LAYRARGUES, 2006).

Como proposição à inserção da temática ambiental urbana em meio escolar, o presente trabalho apresenta a possibilidade que o Planejamento da Revbea, São Paulo, V. 11, № 1: 37-53, 2016. 
Paisagem abre na dimensão ambiental da educação. A proposta é justificada uma vez que a participação da sociedade é base à efetivação de políticas voltadas à proteção do meio ambiente. A metodologia aqui discutida apresenta um exemplo de tratamento da temática dentro de sala de aula.

\section{Planejamento da paisagem e cartografia de biótopos}

Tratando-se de ambiente urbano, residência de $84,35 \%$ da população brasileira (IBGE, 2011), espaço reduzido e denso que, na realidade brasileira, cresce de modo espontâneo e anárquico e sem acompanhamento concomitante da implantação de infraestrutura urbana adequada, gera, além de problemas sociais, a destruição de recursos de valor ecológico.

Quando superado o crescimento espontâneo e desordenado, as cidades se deparam com problemas ambientais planejados. Para Sukopp e Kunick (1973, apud CAVALHEIRO, p. 65):

A discussão sobre o ambiente do ser humano e seus riscos de sobrevivência concentram-se, principalmente, em considerações tecnológicas. A natureza e a paisagem como sistemas complexos raramente são incluídas nessas reflexões. Isso vale, principalmente, para as grandes cidades, o tipo de paisagem mais severamente ameaçado por poluição do ar, das águas e por resíduos sólidos. Embora elas sejam o ambiente mais importante do homem hodierno, são esparsas as tentativas de estudá-las, considerá-las e reconhecê-las como unidades funcionais (ecossistemas).

O Planejamento da Paisagem surge no início do século XIX devido as demandas de uma sociedade moderna em busca, primeiramente, de um embelezamento por si só, mas que, posteriormente, passa a utilizá-lo a fim de controlar a destruição da natureza e o desenvolvimento caótico das cidades (KIEMSTED et al., 1998).

Relacionar todos os aspectos e estruturas da paisagem, e com base no resultado, exprimir de que forma um determinado espaço deverá ser ordenado, obedecendo que o desenvolvimento da sociedade deve salvaguardar a capacidade dos ecossistemas e o potencial recreativo da paisagem como partes fundamentais para a vida humana, é uma contribuição em longo prazo à sociedade. O Planejamento da Paisagem se desenvolve, portanto, conforme uma visão contrária às decisões políticas marcadas pelos interesses econômicos de curto prazo.

O mapeamento das informações referentes ao uso e cobertura do solo é uma importante ferramenta para o planejamento, permitindo o conhecimento e apropriação do espaço para posterior orientação de seu uso racional. 
A cartografia de biótopos (BEDÊ et al., 1997) surge então como uma possibilidade, uma vez que diagnostica uma superfície baseada na integração de diversos parâmetros ecológicos. No mapeamento dessas unidades de paisagem denominadas biótopos, a superfície é desmembrada em unidades cartográficas de uso e estrutura ambiental semelhantes, concomitantemente com uma caracterização detalhada de cada unidade.

No meio urbano existe grande heterogeneidade de superfícies. Diferenças de gabaritos e das densidades de edificações, grau de impermeabilização das áreas livres e etc., criam, em cada unidade, características específicas nas condições climáticas e na biota, que, por fim, criam diversas identidades ecológicas dentro de um mesmo espaço urbano (BEDÊ et al., 1997).

O município de Berlim, na Alemanha, é um exemplo de entendimento por parte do poder público perante a necessidade de proteção dos ecossistemas. O mapeamento dos biótopos é a base mais importante para o Programa de Planejamento de Proteção de Biótopos e Espécies (VALASKI, 2013, p. 80), desenvolvido dentro do Programa da Paisagem incluindo Conservação da Natureza (Landschaftsprogramm - LaPro). A municipalidade compreendeu que "o desenvolvimento da cidade voltado ao futuro será garantido somente se as condições naturais e as exigências ambientais forem levadas em conta" (BERLIN, 2013).

\section{Participação popular e educação para cidadania}

A ideia de liberdade de expressão e de respeito às reivindicações populares é um dos marcos e características das sociedades modernas, que vivem, em sua maioria, no sistema político democrático. Para Bugs e Gonçalves (2010) a participação popular sobre o planejamento urbano ganhou amplo destaque nos últimos anos, principalmente após a aprovação do Estatuto das Cidades em 2001, e, para Silva (2011), o estatuto reafirmou o que já estava garantido pela Constituição, além de incluir três artigos que garantiram a participação popular no planejamento e gestão das cidades.

Existe no contexto brasileiro uma realidade que dificulta a real democracia no momento das tomadas de decisões. Em uma sociedade marcadamente desigual o que se vê são diferentes poderes políticos e econômicos, diversos interesses, e acesso nem sempre homogêneo ao poder; é o que Villaça (2005) chama de "llusão da Participação Popular". O mesmo autor afirma, porém, que nos últimos anos houve avanços democráticos nas discussões, por meio dos debates e audiências públicas sobre os Planos Diretores e Planos Regionais. Santos (2006, p. 86) ainda diz que a participação democrática depende de três fatores: a sobrevivência do indivíduo estar garantida, liberdade e acesso à informação.

Valaski (2013) faz um apanhado em relação a como o poder público deve favorecer a participação e oferecer informações para que os cidadãos tenham pleno entendimento e envolvimento com as intervenções planejadas, Revbea, São Paulo, V. 11, № 1: 37-53, 2016. 
valendo destacar: informar à população sobre seus direitos, responsabilidades e opções; poder público e sociedade devem se comunicar de modo simples e objetivo, permitindo que o cidadão compreenda por meio de linguagem fácil, enxuta e despida de jargão; incentivo e capacitação por parte do urbanista para a participação comunitária; e informar, dar conhecimento e disponibilizar informação.

O Planejamento, por atuar diretamente sobre a paisagem, não é uma questão apenas para peritos, autoridades e associações representativas, diz respeito a todos, particularmente às comunidades locais (KIEMSTED et al., 1998).

Em se tratando de comunidades a educação passa a ter papel decisivo. Aqui se acredita na educação como uma ferramenta base para a mudança cultural e a mudança social. A educação como maior aparelho de difusão ideológica, promove o convívio durante longo tempo entre produtores e consumidores de ideologias.

Para Layrargues (2006, p.5), a educação ambiental "deveria ser analiticamente enquadrada na perspectiva de uma prática pedagógica destinada seja a manter ou alterar as relações sociais historicamente construídas, mesmo que essa prática pedagógica não seja destinada exatamente ao convívio social, mas ao convívio humano com a natureza".

Partindo-se deste pressuposto, a educação ambiental querendo ou não alterar as bases sociais, pode e deve modificar estruturas culturais, servindo como uma lupa a mostrar (ao menos) desequilíbrios ecológicos e incentivar a participação de todos em processos que lhes afetem.

A educação escolar passa a ter papel decisivo na criação da cultura de compreensão do espaço e interpretação dos elementos ambientais. $O$ aluno, ao identificar aspectos da paisagem que podem ser favoráveis ou não ao seu bem-estar e à proteção da capacidade dos ecossistemas, cria um posicionamento crítico e atento às modificações ambientais que os cerca. $A$ educação, portanto, servindo como uma ferramenta poderosa para "despertar um espírito de responsabilidade comunitário e uma resistência aos projetos de diminuição da qualidade ambiental urbana" (NUCCl, 2008, p.129).

Steiner (2008, p.10), em seu modelo ecológico, mostrou que o processo de planejamento passa por onze passos inter-relacionados (Figura 1).

O autor destaca que "o envolvimento popular é importante em cada etapa, mas especialmente no passo oito, quando é explicado ao público" (p. 10, tradução nossa). Para ele o sucesso de um plano depende muito de como a população atingida é envolvida durante todo o processo de planejamento. A incorporação das ideias da comunidade resultará em apoio local e maior monitoramento da população durante a execução (p. 21). 


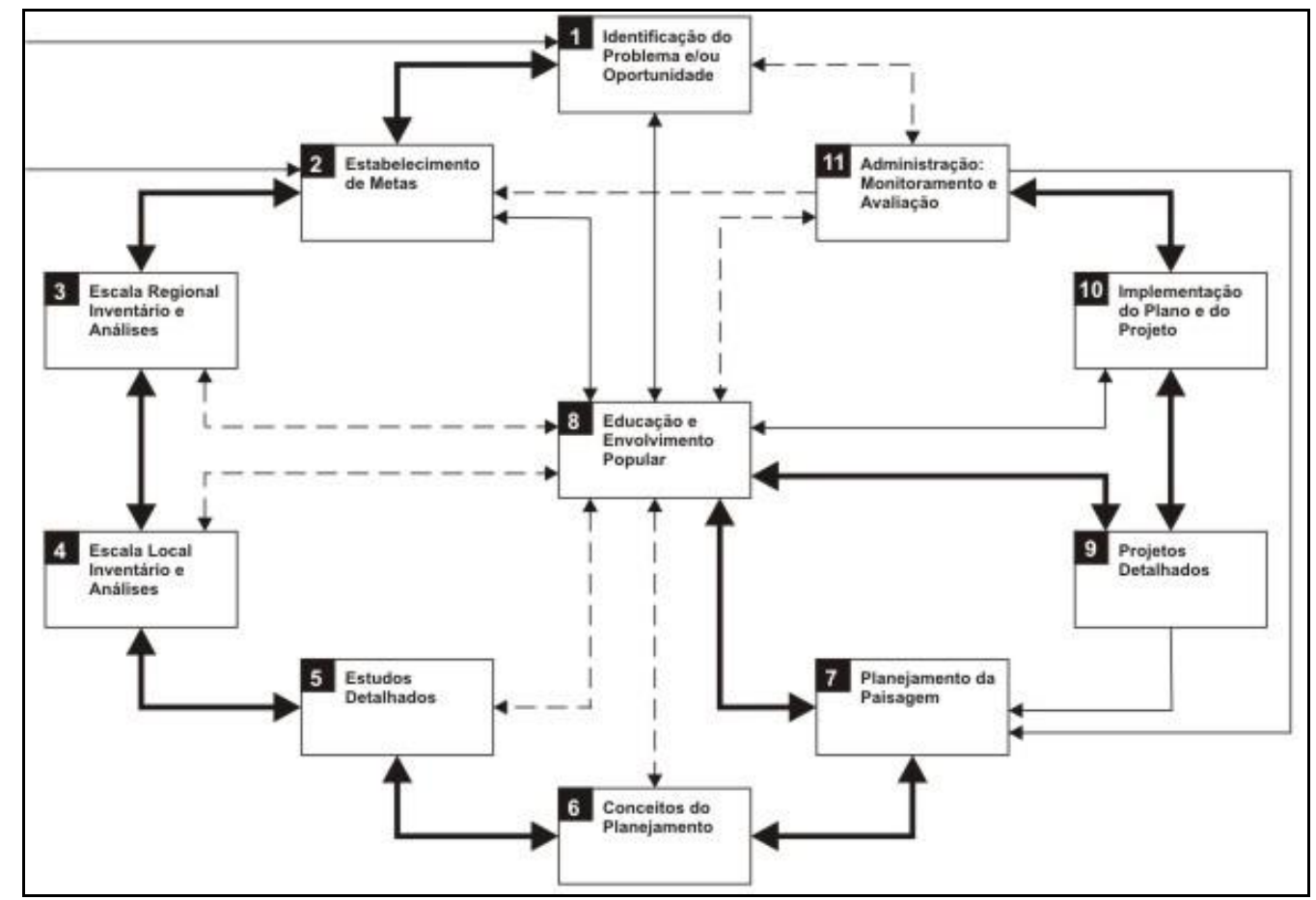

Figura 1: Modelo do processo de planejamento ecológico.

Adaptado de: Steiner (2008). Organização: dos autores.

\section{Aplicando ao cotidiano}

Valaski (2013), ao analisar a cobertura do solo no município de Curitiba, propôs uma chave classificatória com inferências sobre a dinâmica da paisagem com base em sua estrutura evidenciada na cobertura do solo, desenvolvendo um método que permite o mapeamento da cobertura do solo relacionado à inferência da qualidade ambiental. Para a autora, o aumento da quantidade de vegetação, dos espaços livres de edificação e predomínio de edificações baixas são atributos que contribuem para uma melhora da qualidade ambiental de áreas urbanizadas, aspectos abordados de modo mais aprofundado em Nucci (2008).

O mapeamento da cobertura do solo permite aos educandos 0 conhecimento e a qualificação da realidade com base em imagens de satélite, criando uma visão contestadora em relação aos projetos urbanísticos vigentes nas cidades. A realidade imediata torna-se o principal campo para compreensão e monitoramento por parte dos alunos, e seu mapeamento transforma-se em um momento de apropriação das informações do espaço. A cartografia de biótopos é uma ferramenta para extração de informações ambientais multidisciplinares que permite a compreensão das relações ecológicas da comunidade próxima; por exemplo, a vizinhança da escola.

A fim de apresentar o método e propor um trabalho que possa ser desenvolvido no âmbito da educação ambiental, escolheu-se como área teste o bairro Portão, em Curitiba (PR).

Revbea, São Paulo, V. 11, № 1: 37-53, 2016. 
O mapeamento foi realizado por meio da interpretação das imagens de satélites disponíveis gratuitamente no software Google Earth; a base cartográfica de 2011 foi disponibilizada pelo Instituto de Pesquisa e Planejamento Urbano de Curitiba (IPPUC); e a classificação da cobertura do solo foi feita no sofware Arc GIS 9.3. Materiais mais simples e passíveis de manuseio em sala de aula podem ter os mesmos resultados. A escala espacial para o mapeamento foi de 1:5.000, considerada o ideal para esse tipo de análise no meio urbano (VALASKI, 2013, p. 87).

A imagem de satélite utilizada, de 25 de abril de 2013, foi interpretada a partir de técnicas de fotointerpretação, as quais permitem a identificação dos objetos e sua avaliação qualitativa. A base de arruamento foi sobreposta à imagem, e assim cada quarteirão foi classificado. A fim de classificar mais detalhadamente, em alguns casos a base foi recortada, o que permitiu, respeitando a escala espacial do mapeamento, a identificação de mais de uma classe por quarteirão.

\section{Mapa e chave classificatória}

O bairro Portão localiza-se na porção central do município de Curitiba (Figura 2), dentro da Regional Portão. Apresenta 42.662 habitantes, com uma densidade demográfica de 72,82 hab/ha (IPPUC, 2013, p. 5), e funciona como um polo de comércio e serviços também aos moradores dos bairros próximos.

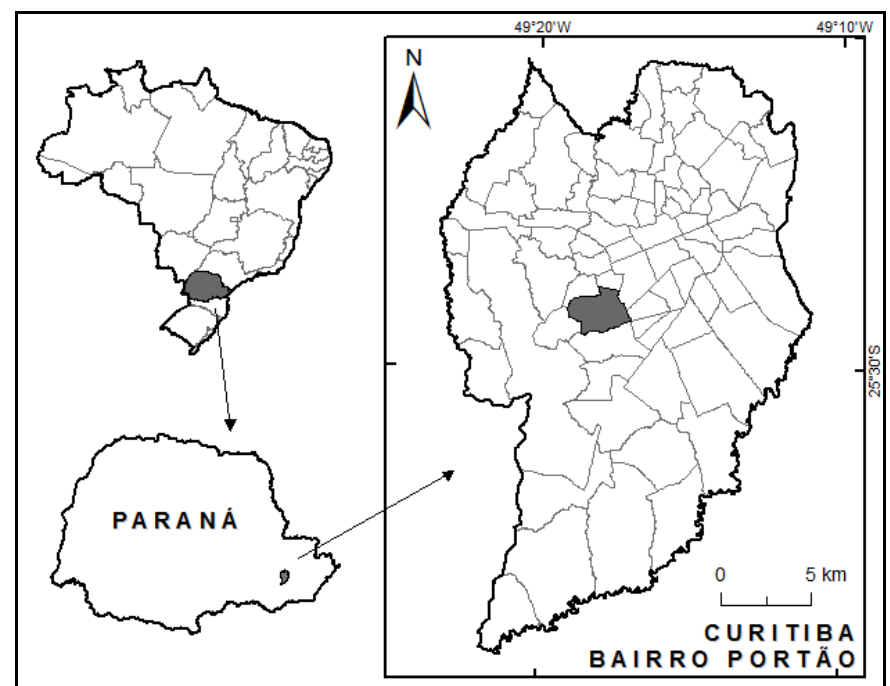

Figura 2: Localização do bairro Portão. Fonte: IPPUC. Elaboração: os autores.

Com base na proposta de Valaski (2013), foram classificadas 19 classes no mapeamento do bairro Portão (Figura 3). Foram realizadas três adaptações: as classes 1.8 e 1.9 passaram a ser chamadas por "Grandes edificações" ao invés de "Área com aspecto industrial, grandes galpões"; e a classe 1.10, Urbanização precária, foi incluída. 
1 ESPAÇOS EDIFICADOS:

1.1 Edificações baixas (até quatro pavimentos) com jardim grande

1.2 Edificações baixas (até quatro pavimentos) com jardim ou horta

1.3 Edificações baixas (até quatro pavimentos) sem jardim, solo bastante impermeabilizado

1.4 Edificações com mais de quatro pavimentos e edificações baixas com jardim

1.5 Edificações com mais de quatro pavimentos e edificações baixas sem jardim, solo bastante impermeabilizado

1.7 Edificações com mais de quatro pavimentos sem jardim, solo bastante impermeabilizado

1.8 Grandes edificações com vegetação

1.9 Grandes edificações com solo bastante impermeabilizado

1.10 Urbanização precária

\section{TRANSPORTES}

5.1 Terminais de ônibus urbanos

Figura 3 : Legenda para classificação da cobertura do solo do bairro Portão, Curitiba.

$\mathrm{Na}$ Figura 4 foram relacionadas as classes da legenda dos espaços edificados com a qualidade ambiental. Os espaços não edificados, exceto a classe 3.11, contribuem, em diferentes graus, positivamente à qualidade ambiental urbana.

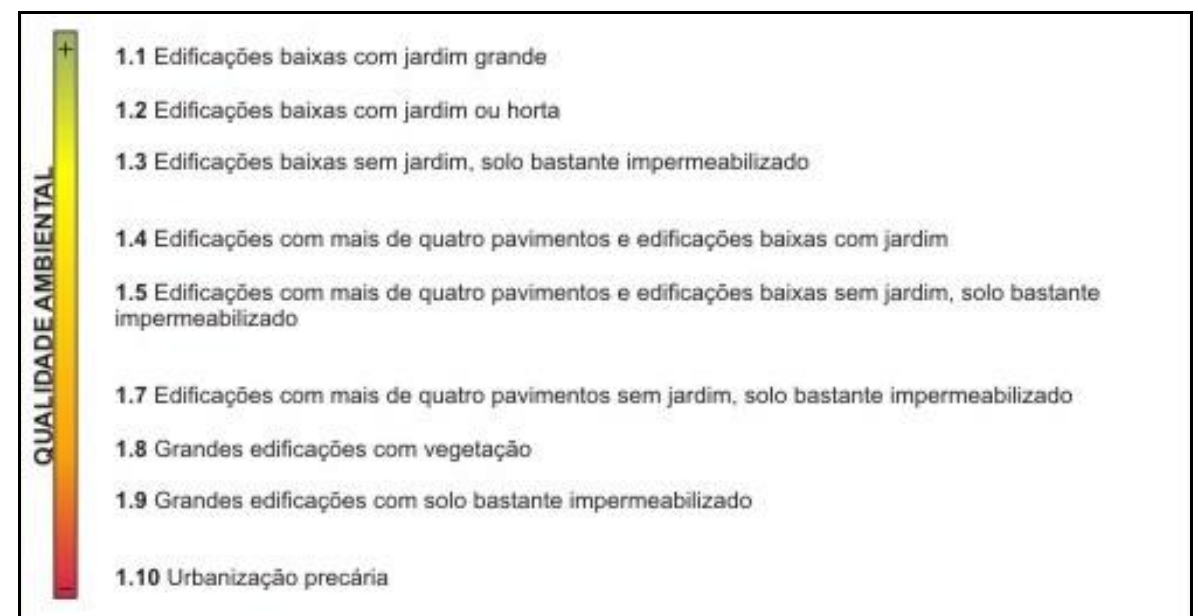

Figura 4: Relação entre espaços edificados e qualidade ambiental. Adaptado de: Valaski, 2013. Organização: dos autores.
3.1 Praças

3.2 Praças pequenas

3.3 Parques / Bosques públicos

3.6 Vegetação arbórea (fragmentos de floresta)

3.7 Vegetação arbórea, arbustiva e herbácea

3.8 Vegetação arbustiva e herbácea

3.9 Vegetação herbácea

3.10 Solo exposto

3.11 Solo totalmente impermeabilizado

\section{ESPAÇOS NÃO EDIFICADOS:}

A Figura 5 apresenta a espacialização dos biótopos do bairro realizada a fim de expor a possibilidade do uso do método em sala de aula. 


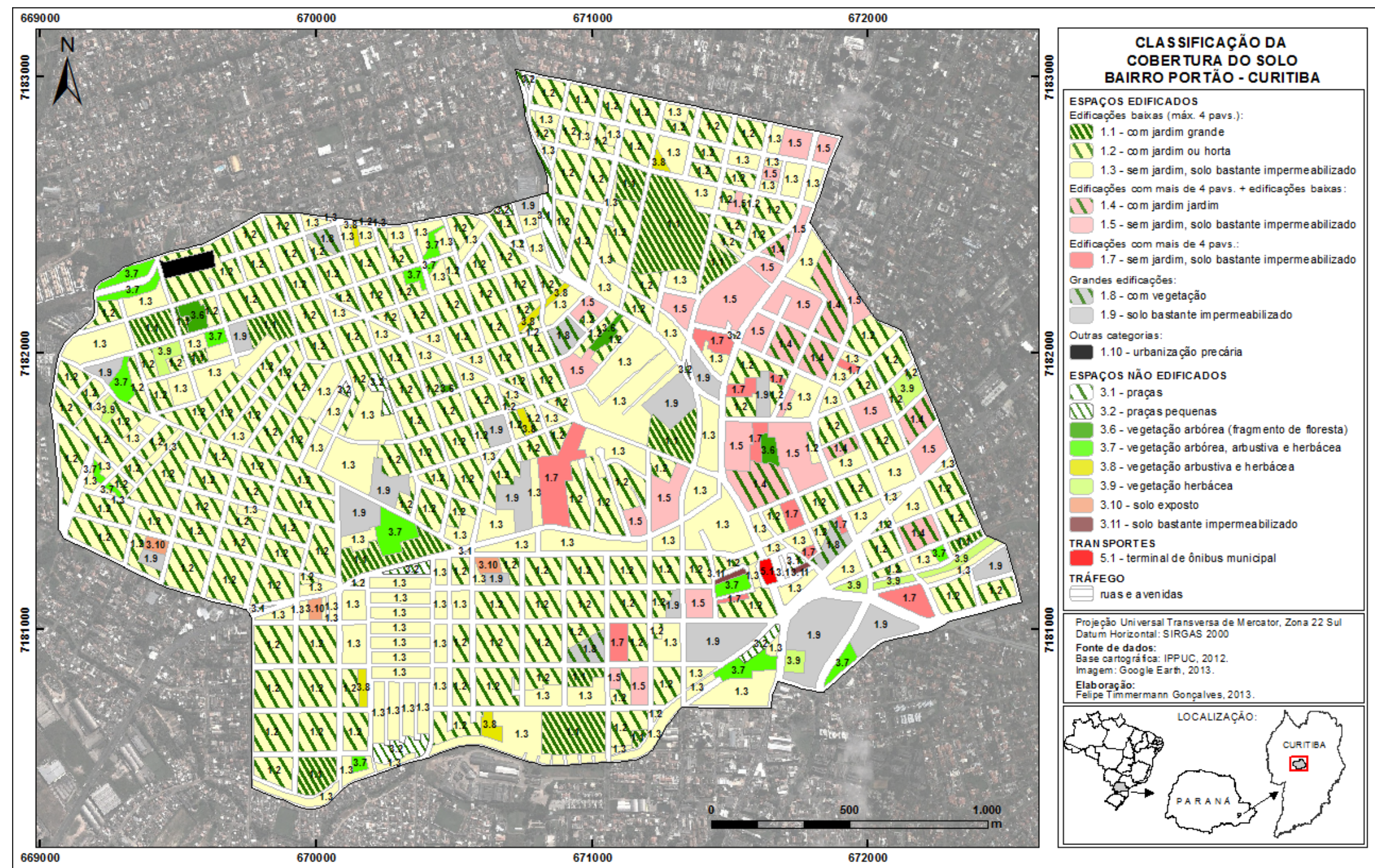

Figura 5: Mapeamento da cobertura do solo do bairro Portão, Curitiba 
A fim de interpretar detalhadamente a paisagem classificada no mapeamento, foi organizada a chave classificatória, na qual foram feitas inferências sobre a dinâmica e estrutura de cada unidade de paisagem. A chave classificatória é composta, para cada unidade, por uma imagem de satélite, um esquema ilustrativo e uma foto tirada no nível do solo. As imagens são disponibilizadas pelo software Google Earth, e os esquemas desenhados no software Corel Draw 13. Junto às imagens foi feita uma descrição dos aspectos da estrutura e da dinâmica das unidades que são decisivas à qualidade ambiental destas.

A linguagem simplificada e a utilização de recursos visuais na chave classificatória auxiliam a compreensão da estrutura da paisagem, uma vez que ela traduz aspectos importantes da dinâmica espacial em uma linguagem acessível a todos. A chave classificatória para o bairro Portão está representada nas Figuras 6a, b, c, d, e.

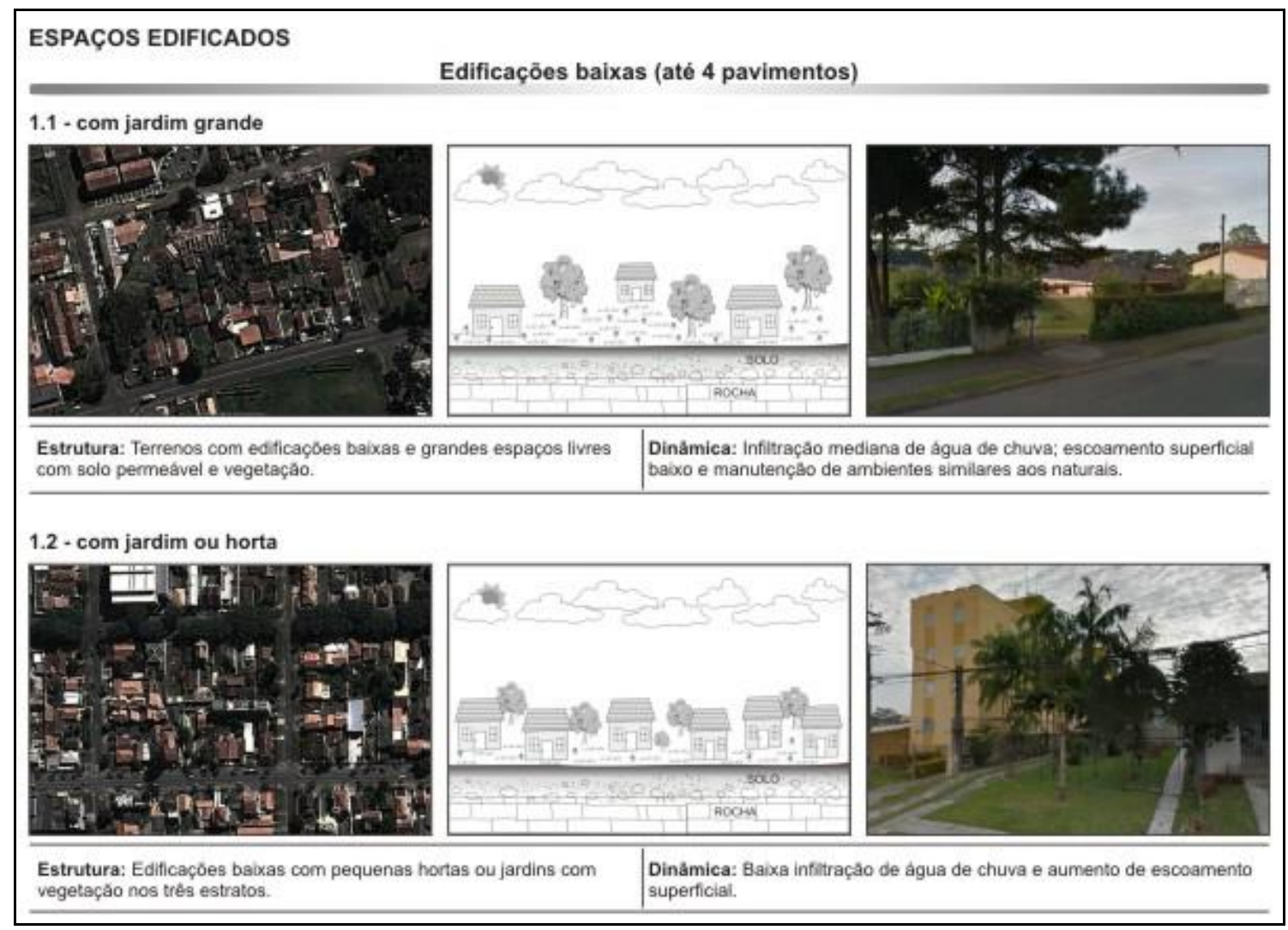

Figura 6a: Chave classificatória com inferências (parte 1) 


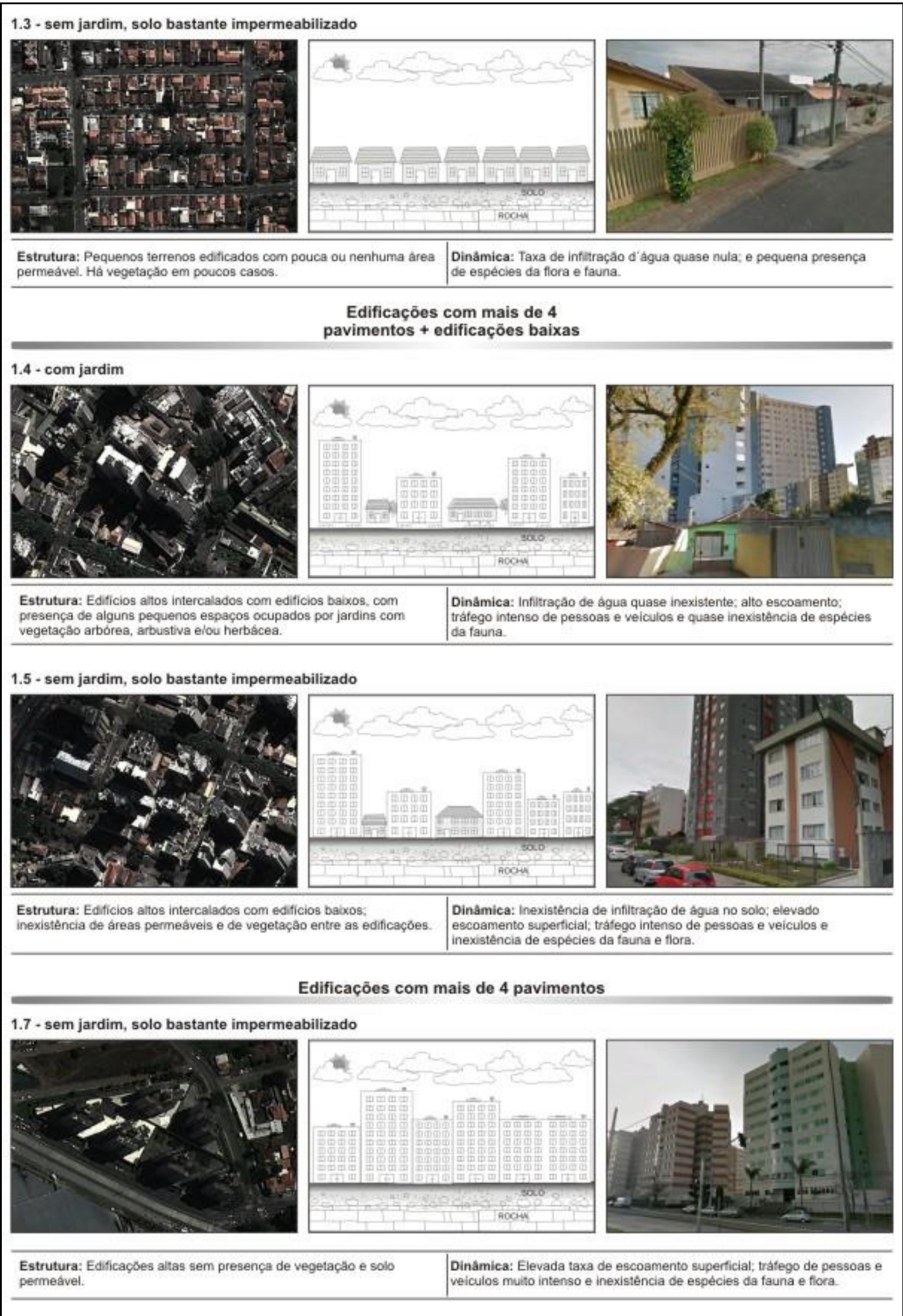

Figura 6b: Chave classificatória com inferências (parte 2)

Revbea, São Paulo, V. 11, № 1: 37-53, 2016. 


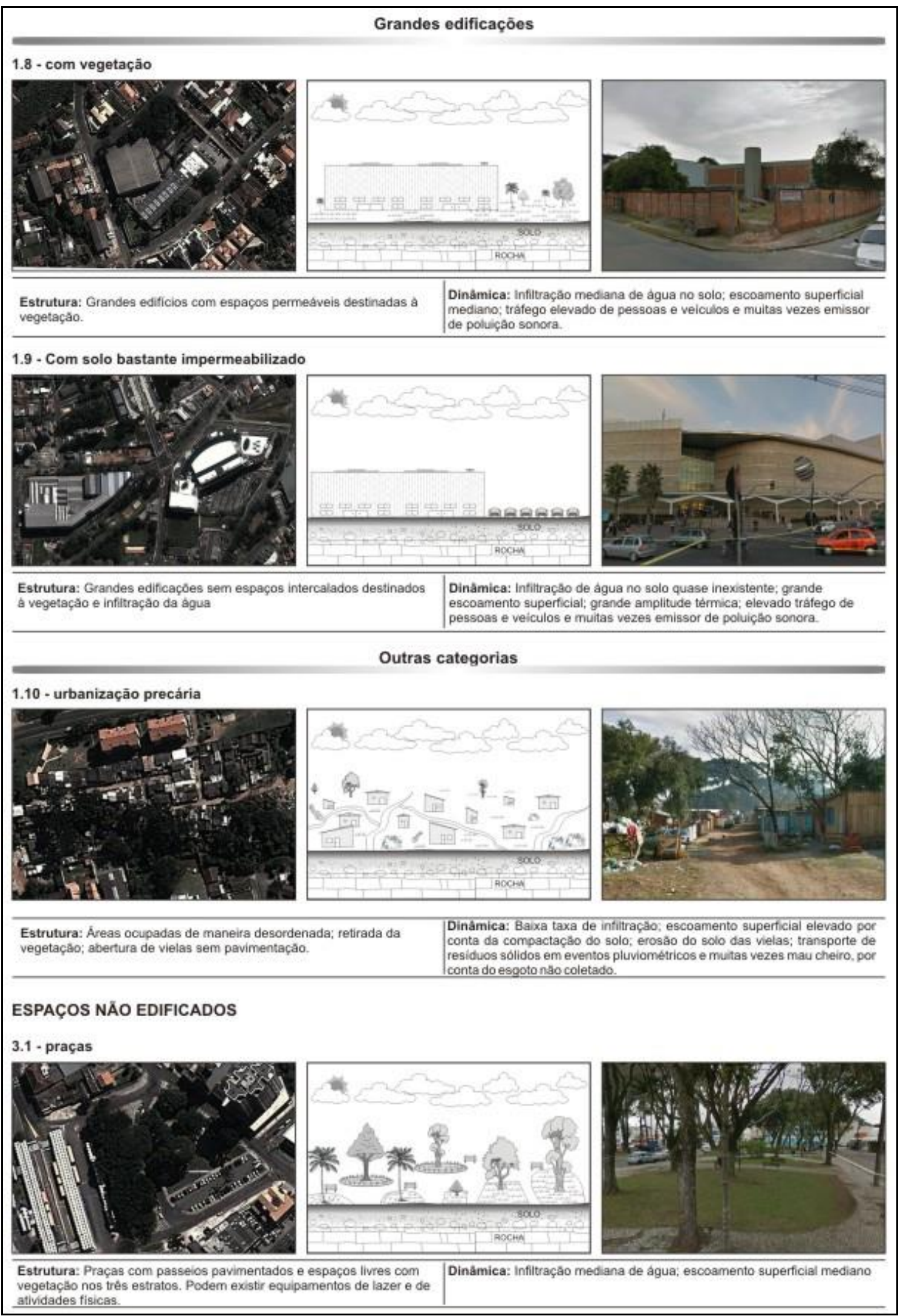

revista brasileira de educação ambiental
Figura 6c: Chave classificatória com inferências (parte 3).

Revbea, São Paulo, V. 11, № 1: 37-53, 2016. 


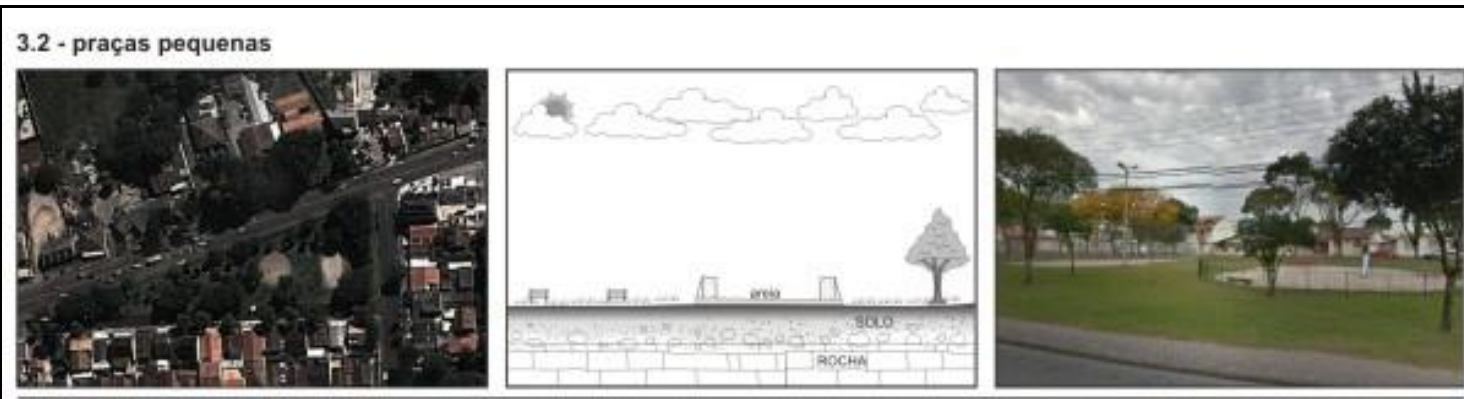

Estrutura: Pequenos espaços livres de edificaçðes, tendo como funçăo Dinämica: Alta taxa de infiltraçăo de água no solo e pouca variedade de principal a proteçầ de areas suscetiveis a inundaçăo. Podem ter flora e fauna.

equipamentos de lazer e de atividades fisicas.

\section{3 - parques / bosque públicos}
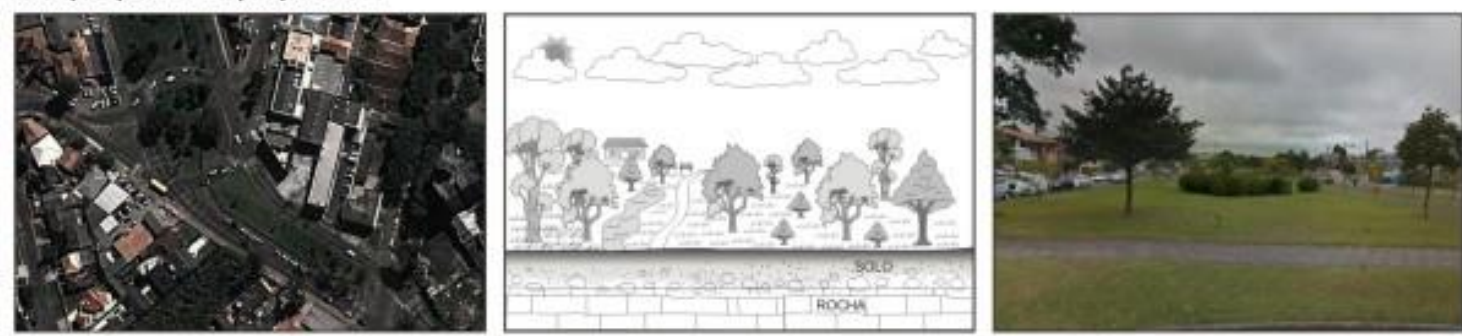

Estrutura: Grandes espaços destinados a recreaçăo e manutençâo da vegetaçăo em seus trés estratos.

Dinåmica: Alta taxa de infiltraçăo de água no solo; variedade mediana de flora e fauna e pouca alteraçăo dos aspectos climáticos daquele espaço

\section{ESPAÇOS NĀO EDIFICADOS}

\section{6 - vegetação arbórea (fragmentos de floresta)}
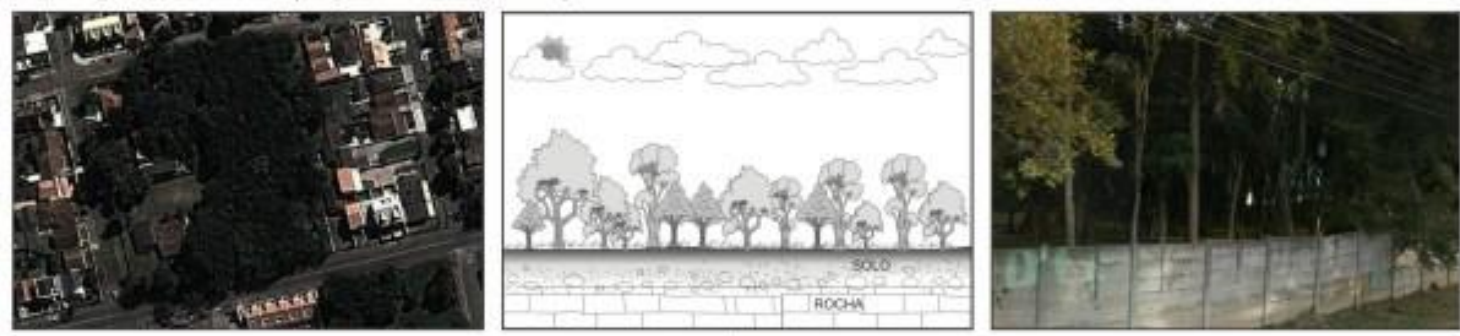

Estrutura: Terreno sem edificaçóes e com predominio de vegetaçăo arborea, caracterizando um fragmento de floresta.

Dinamica: Alta taxa de infiltraçăo de água no solo e baixissima de escoamento superficial; grande variedade de flora e fauna e alta taxa de evapotranspiraçăo.

\section{7 - vegetação arbórea, arbustiva e herbácea}
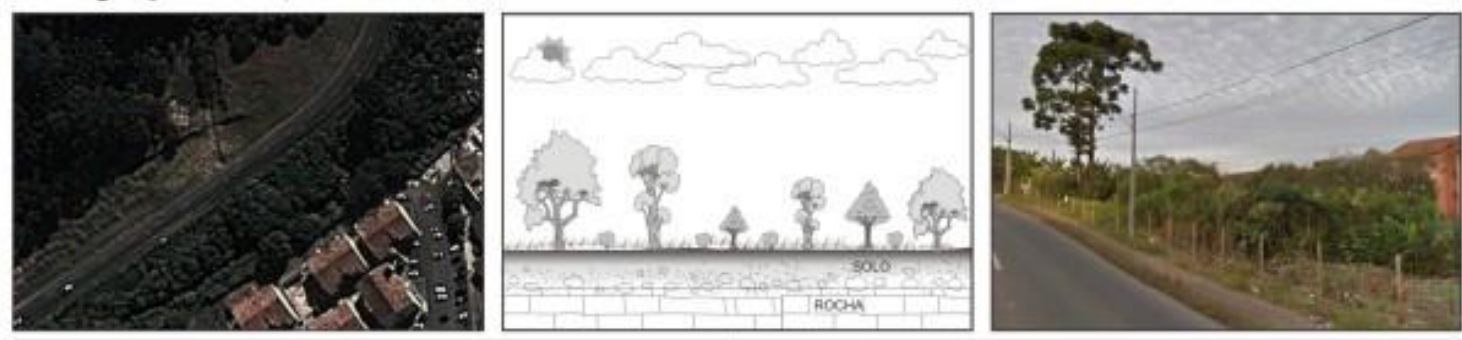

Estrutura: Terreno sem edificaçôes e com vegetaçăo nos tres estratos. porém apresenta individuos um pouco esparsos, năo caracterizando

Dinâmica: Infiltraçầ de água mediana; escoamento superficial mediano: fragmento florestal. baixa ampli

Figura 6d: Chave classificatória com inferências (parte 4). 


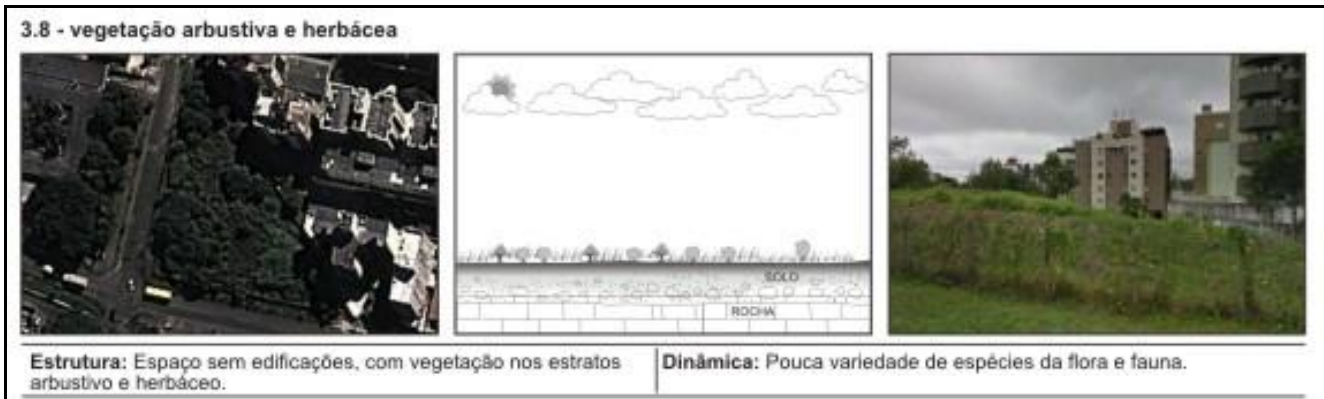

3.9 - vegetaçào herbácea
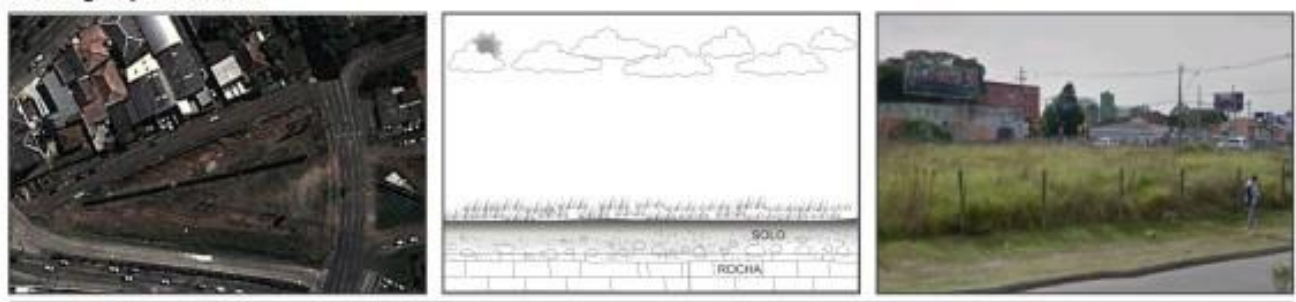

Estrutura: Terreno sem edificaçoes, com vegetaçăo herbácea.

Dinàmica: Pouca variedade de espécies da flora e fauna

3.10 - solo exposto
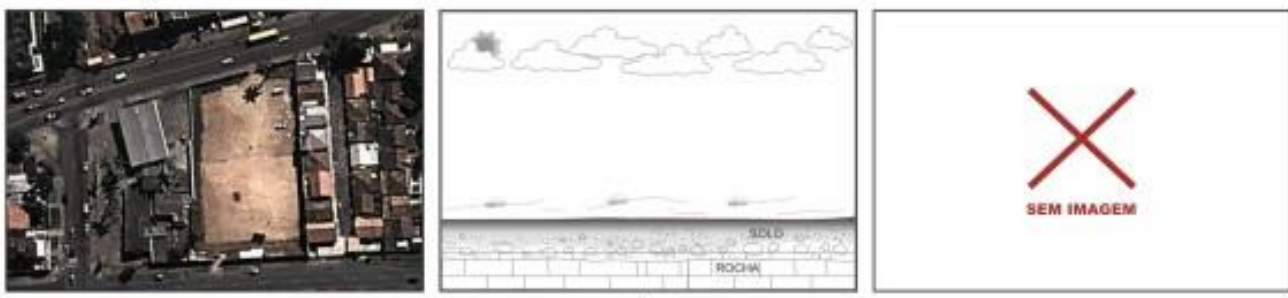

Estrutura: Terreno sem edificaçoes e sem vegetaçăo.

Dinamica: Baixa taxa de infiltraça associada a alta taxa de escoamento superficial; elevada atividade erosiva e aumento da

3.11 - solo totalmente impermeabilizado
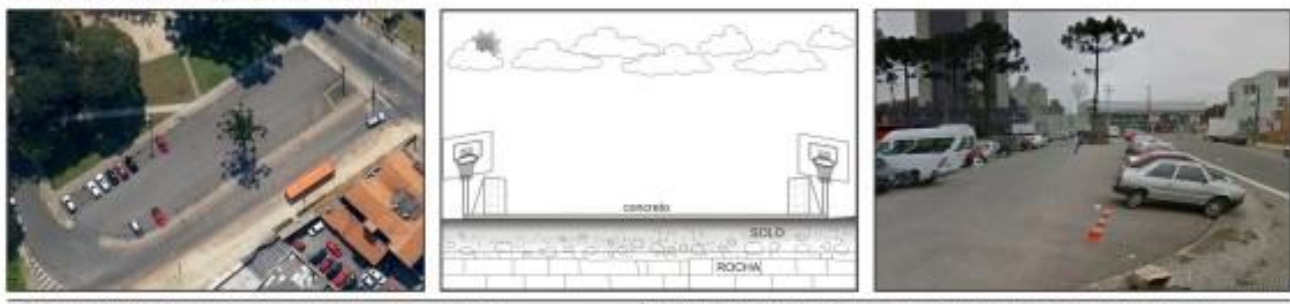

Estrutura: Grandes espaços sem edificação, com solo

Dinåmica: Infiltraçåo de água inexistente; escoamento elevado; impermeabilizado, normalmente destinado a quadras esportivas ou grande amplitude térmica e inexistência de espécies da fauna e flora.

\section{TRANSPORTES}

5.1 - terminais de ônibus urbanos

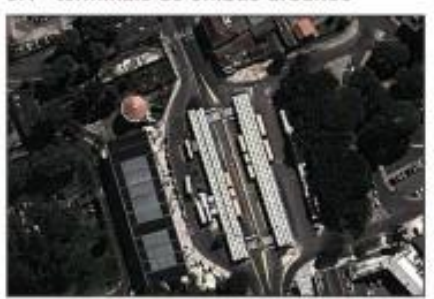

Estrutura: Espaço totaimente impermeabilizado por conta da construçáo de edificaçáo e vias internas do terminal.

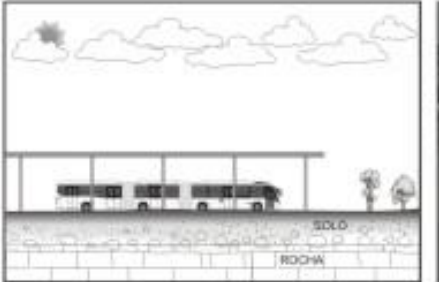
escoamento superficial; grande movimentaçăo de pessoas e veiculos pesados e grande fonte de poluiça.
Figura 6e: Chave classificatória com inferências (parte 5).

Revbea, São Paulo, V. 11, № 1: 37-53, 2016. 
Após o mapeamento e adaptação da chave de classificação das paisagens, diversos temas podem ser abordados, tais como as leis de ordenamento do solo, a qualidade ambiental do bairro e aspectos históricos da ocupação do bairro e da cidade que influenciam a paisagem até o presente. Portanto, a interdisciplinaridade, fundamental à educação ambiental, é fato presente no uso do método.

\section{Resultados e discussões}

O exemplo do bairro Portão mostra um predomínio de edificações baixas no bairro, porém, com algumas aglomerações de outras classes que deverão ser compreendidas.

Na porção leste é visível a aglomeração das edificações com mais de cinco pavimentos, o que acarreta em perda da qualidade ambiental à comunidade. O mapa do zoneamento do uso do solo do município de Curitiba (CURITIBA, 2000) explica tal aglomeração, e deve ser uma ferramenta de suporte para entender as paisagens da comunidade. Também, entender porquê aquela região foi escolhida para ser o eixo de crescimento da cidade, abordará aspectos ecológicos importantes para a compreensão do espaço, uma vez que tal eixo marca o limite de duas bacias hidrográficas da cidade, a do rio Barigui a oeste, e do rio Belém a leste. Estas áreas se configuram como as mais densas e modificadas da cidade. Grandes edificações e fluxo intenso de veículos tornam esses espaços como os de mais baixa relação de qualidade ambiental no ambiente urbano (VALASKI, 2013). Trabalhos de campo poderão servir para a percepção do espaço aos alunos, a fim de vivenciar as diferenças de qualidade ambiental entre as regiões densamente ocupadas e as com predominância de edificações baixas.

A aglomeração de grandes edificações na porção sudeste do bairro causa grande diminuição ao bem estar da população que ali convive, o que seria facilmente perceptível em uma visita de campo. Por se tratar de centros de compras e supermercados, as pessoas da região, além de conviver com as grandes edificações que danificam as características naturais do espaço, também convivem com o fluxo elevadíssimo de pessoas e veículos, o que gera diversas formas de poluição.

\section{Considerações finais}

O método de mapeamento da estrutura da paisagem e as respectivas inferências da dinâmica proposto por Valaski (2013) permite que diversos aspectos ecológicos sejam trabalhados de modo relacionado e interdisciplinar. O resultado do mapeamento transforma a informação primária contida na imagem de satélite em diversas informações secundárias qualificadas, que permitem a interpretação do espaço e seus elementos.

Por ser um trabalho baseado no conceito de paisagem, o enfoque foi geográfico e ecológico (ou geoecológico), porém, o uso de tal ferramenta em

revista brasileira educação ambiental 
sala de aula é aproveitável também em outras disciplinas, resultando em um trabalho de educação ambiental com integração entre diversas áreas do conhecimento.

O mapeamento das paisagens faz surgir novas questões como, por exemplo, os motivos que levam a áreas tão próximas terem ordenamentos do solo diferenciados. Leis ambientais e de zoneamento, notícias, levantamentos históricos, histórias pessoais e tantos outros elementos, podem ser trabalhados conjuntamente a fim de responder sobre os diversos elementos da vizinhança da escola, permitindo que o aluno tenha uma visão curiosa, criativa e crítica sobre a realidade do seu espaço cotidiano.

Este trabalho buscou apresentar uma ferramenta do Planejamento da Paisagem que pode ser utilizada no espaço escolar. Seu uso pode trazer resultados positivos, e abranger objetivos fundamentais da Educação Ambiental contidos em lei, como o inciso I do Artigo 5o da Lei 9.795:

I - o desenvolvimento de uma compreensão integrada do meio ambiente em suas múltiplas e complexas relações, envolvendo aspectos ecológicos, psicológicos, legais, políticos, sociais, econômicos, científicos, culturais e éticos. (BRASIL, 1999)

Com base nesta proposta novas abordagens e enfoques propondo aplicações mais concretas deverão se desenvolver, sempre buscando estimular no aluno sua função consciente e interventora sobre as políticas públicas.

\section{Referências}

BEDÊ, L.C. et al. Manual para Mapeamento de Biótopos no Brasil: base para um planejamento ambiental eficiente. 2 ed. Belo Horizonte: Fundação Alexandre Brandt, 1997, 146p.

BELEM, A.L.G. Unidades de Paisagem no bairro de Santa Felicidade (Curitiba$\mathrm{PR}$ ), propostas ao planejamento e ordenamento da paisagem. $88 \mathrm{f}$. Dissertação (Mestrado em Geografia) - Setor de Ciências da Terra, Universidade Federal do Paraná, Curitiba, 2013.

\section{BERLIN. Senatsverwaltung für Stadtentwicklung und Umwelt - Landschaftsplanung. Disponível em: $<$ http://www.stadtentwicklung.berlin.de/umwelt/landschaftsplanung $>$. Acesso em: 01/10/2013.}

BRASIL. Lei no 9.795, de 27 de abril de 1999. Dispõe sobre a educação ambiental, institui a Política Nacional de Educação Ambiental e dá outras providências. Presidência da República. Disponível em: $<$ http://www.planalto.gov.br/ccivil 03/Leis/L9795.htm>. Acesso em: 22/10/2013. 
BUGS, G.; GONÇALVES, A.R. Uso da Cartografia Digital Interativa para Participação Popular na Gestão e no Planejamento Urbano. Simpósio Integrado de Geotecnologias do Cone Sul - SIG-SUL 2010. Anais... Centro Universitário La Salle - Unilasalle, Canoas.

CAVALHEIRO, F. Urbanização e Alterações Ambientais. In: SANTOS, D.G.; NUCCl, J.C. (Org.) Paisagens Geográficas: um tributo a Felisberto Cavalheiro. Campo Mourão: Editora da FECILCAM, 2009.

CURITIBA. Lei no 9.800, de 03 de janeiro de 2000. Dispõe sobre o Zoneamento, Uso e Ocupação do Solo no Município de Curitiba e dá outras providências. Prefeitura Municipal de Curitiba.

IBGE. Censo Demográfico 2010. Rio de Janeiro, 2011.

IPPUC. Instituto de Pesquisa e Planejamento Urbano de Curitiba. Retrato das Regionais: Regional Portão. Curitiba: IPPUC, 2013. Disponível em: $<$ http://www.ippuc.org.br/>. Acesso em: 28/10/2013.

KIEMSTED, H.; von HAAREN, C.; MÖNNECKE, M.; OTT, S. Landscape Planning: contents and procedures. Hanover: The Federal Ministry for the Environment, Nature Conservation and Nuclear Safety, University of Hanover, 1998, 39p.

LAYRARGUES, P.P. Muito além da natureza: educação ambiental e reprodução social. In: LOUREIRO, C.F.B.; LAYRARGUES, P.P; CASTRO, R.C. de (Orgs.). Pensamento complexo, dialética e educação ambiental. São Paulo: Cortez, 2006. p. 72-103.

$\mathrm{NUCCI}$, J.C. Qualidade ambiental e adensamento urbano: um estudo de ecologia e planejamento da paisagem aplicado ao distrito de Santa Cecília (MSP). 2 ed. Curitiba: o autor, 2008. 150 p.

SILVA, P.C. Participação Popular no Planejamento das Cidades: o Programa Cidade pra Gente nos municípios de Goiatuba e Mineiros. 135 f. Dissertação (Mestrado em Arquitetura e Urbanismo) - Faculdade de Arquitetura e Urbanismo, Universidade de Brasília, Brasília, 2011.

STEINER, F. The living landscape: an ecological approach to landscape planning. 2 ed. Island Press: Washington, 2008.

VALASKI, S. Estrutura e Dinâmica da Paisagem: subsídios para a participação popular no desenvolvimento urbano do município de Curitiba-PR. $149 \mathrm{f}$. Tese (Doutorado em Geografia) - Setor de Ciências da Terra, Universidade Federal do Paraná, Curitiba, 2013.

VILLAÇA, F. As ilusões do Plano Diretor. São Paulo, 2005. Disponível em: $<$ http://www.flaviovillaca.arq.br/pdf/ilusao pd.pdf>. Acesso em: 21/09/2013.

Agradecimentos: Os autores agradecem o apoio financeiro do CNPq pela concessão das bolsas de iniciação científica ao primeiro autor, de produtividade em pesquisa ao segundo coautor e de doutorado ao terceiro coautor. 